\title{
RESEARCH OF READABILITY AND IDENTIFICATION OF THE ITEMS IN THE POSTAL AND LOGISTICS ENVIRONMENT
}

\author{
Peter Kolarovszki \\ University of Zilina, Faculty of Operation and Economics of Transport and Communications \\ Department of Communications \\ Univerzitná 1, 010 26, Žilina, Slovakia \\ Phone: +421 908227492.E-mail:peter.kolarovszki@fpedas.uniza.sk
}

\begin{abstract}
This article deals with RFID technology, which is a part of automatic identification and data capture. Nowadays, the identification of parcels in postal sector is carried through barcodes. In this article we would like specify, how can be postal parcels located in postal container identified in the transmission process of postal main processing centre by UHF RFID technology. All results are verified by measurement in our AIDC laboratory, which is located at the University of Žilina. Our research contains 12 different types of orientation tags and antennas and more than 1000 tests. Our identification performance was close to $100 \%$. All tested parcels were located in postal container. The results of our research bring the new point of view and indicate the ways using of UHF RFID technology in postal applications. At the end of this article the utilization of the RFID technology in postal logistics chain is characterized.
\end{abstract}

Keywords: RFID technology, logistics chain, parcels, identification, postal container

\section{Introduction}

Technology of automatic identification plays a significant role nowadays in all the fields of economics. Regarding the optimisation of supply chains, the bar code technology is utilized for this purpose in a long term. Technology of radio frequency identification is getting more and more popular considering multitude of advantages and therefore it is highly expected, that its application will be extending further into all the fields of economics, including postal sector. This article deals with an application of RFID technology in the field of postal network optimisation, in particular within processes of identification of parcel posts placed in postal container. The technology of RFID is specified in the article along with performed research of readability of RFID identifiers attached to parcel posts positioned in postal container. Considering the performed research, the layout of placing of particular RFID identifiers on parcel posts has been designed.

\section{Objective and Methodology}

Object of the research are the parcel posts transported in postal containers within postal network consisting of particular components. These shipments contained UHD RFID identifier that was read by use of 2 or 4 antennas of particular scanning device. In order to achieve the relevant results of the research, more than 1.500 measurements were performed by various types of testing. For testing purposes, we used cubicle postal container that is real utilized at transport of parcel posts. Within methodology or series of steps, we chose diagram of partial goals that is depicted in detail on Figure 1.

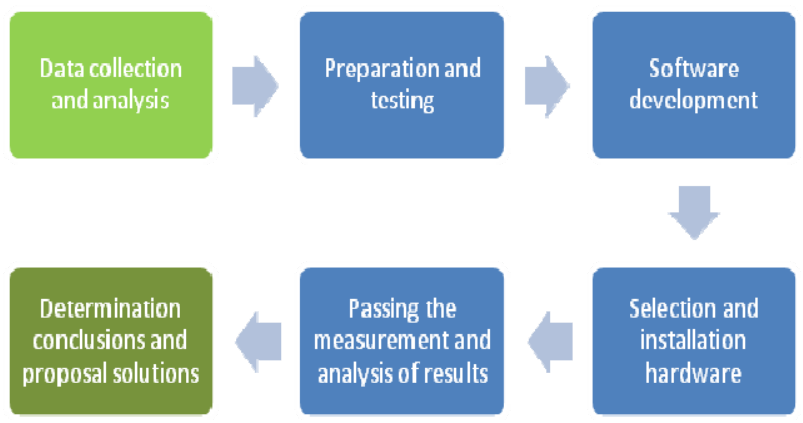

Figure 1. Diagram of partial goals 


\section{Postal Transport Network}

Postal transport (Kolarovszká and Fabuš, 2011) is an important part of the process of filing a postal item to its delivery to the addressee in compliance with established quality standards for different types of mail under postal license requirements and the quality of universal postal service.

Postal transmission network consists of road transport courses and road itinerary. By the structures of postal transmission network there are used various tools and systems. Postal transport network is currently divided into three main levels:

- district transport network (OPS) - connects the establishment and other facilities on the territory of the district processing centre and regional units (OU) with the delivery points,

- regional transport network (RPS) - connects the main processing centres in regional processing centres with their own circuit, the main processing centres with appropriate regional nodes, where each regional processing centres,

- the main transport network (HPS) - connects each major processing centres, the main processing centres with regional processing centres from another circuit HSS, includes transport findings in international relations.

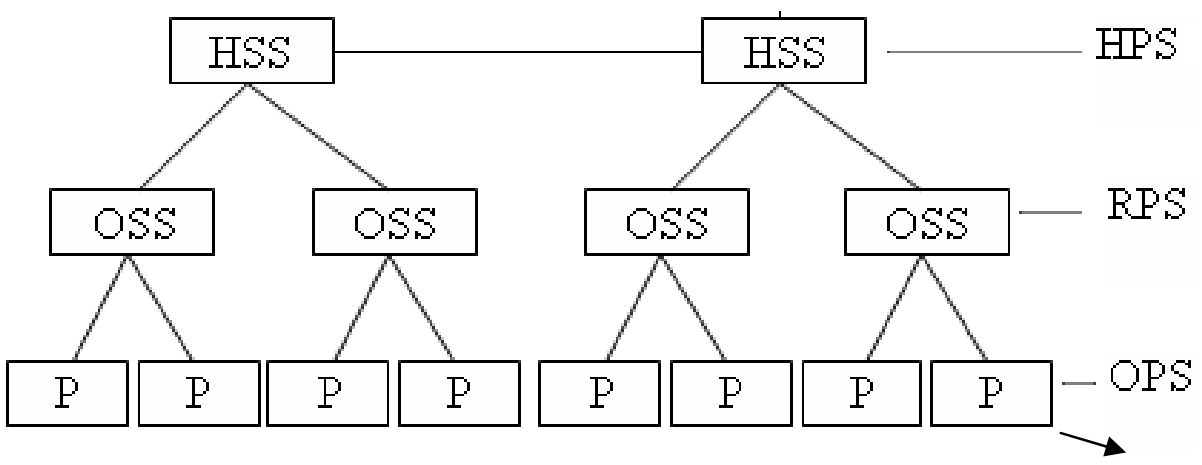

Figure 2. Postal transport network

Post office

In the carriage of postal items is necessary to decide what type of transport used for this purpose, what are the flows of items and what is their intensity. Way to connect and type of vehicle depends on the following factors:

o density and organization of the postal network,

o flows of different types of postal items and their size,

o the carrying capacity of vehicles used,

o transport time of each species of postal items,

o safety and effectiveness of postal traffic.

Processing of items is implemented in the workplace of the Slovak Post:

- $\quad$ HSS - main processing centre - the facility providing treatment and quest items posting its area of perimeter, mail items addressed to your district and in transit in its dealings with OSS circuit, in contact with other HSS and OU,

- $\quad$ OSS - regional processing centre - post office responsible for preparing and quest items posted at post offices in his own constituency and in transit in contact with your postal district and interacted with the HSS, the facility responsible for receiving, processing and quest items express postal services,

- $\quad$ Selected post - post office responsible for preparing and quest items selected species within a specified range (usually as OSS),

- Exchange post - processing the shipment and ensure shipments to post offices exchange foreign postal administrations,

- Regional hub as department of express service - establishment is responsible for receiving, processing and quest items express postal service. 


\subsection{Technological Procedure of Parcel Mails Processing}

The technological procedure of parcels processing consists of several following phases. Parcels assigned for delivery within delivery area of delivery post are left at this post. If the parcels are assigned for delivery out of this delivery area, dispatch is created so that the parcels could be transported from post without sorting procedure into respective OSS/OU. Dispatches are out = carded at OSS/OU with following sorting of parcels for own delivery area and the others. If the parcels are directed our of OSS/OU delivery area, the dispatch is created and parcels are shipped to HSS of mail register.

Parcels are sorted for own delivery area and other HSS manually or by use of auxiliary parcel posts sorting device after out-carding of dispatches into HSS. Out-sorted parcels are stored and later dispatched into respective postal course freely or in containers on the road or by railway. Once the parcels are delivered to respective HSS, the parcels are divided according to type (the $1^{\text {st }}$ and $2^{\text {nd }}$ class) and are placed into separate containers or freely. Prior to the sorting process, bar codes are scanned for the purposes of track-and-trace service. After unloading of shipping containers from postal course mails are sorted in place that is divided into parcel sorting room and trans-loading. There is a sorting of registered mails, express mails and parcels inappropriate for mechanical processing. All the parcels of the $1 \mathrm{st}$ and $2^{\text {nd }}$ class appropriate for mechanical processing are sorted in parcels' sorting room. After that, the dispatches are created and parcels are shipped freely in containers to respective OSS/OU and subsequent to office of delivery.

\section{RFID Technology}

Radio frequency identification (Hunt, Puglia, 2007) is a wireless data collection technology that uses electronic tags, which store data, and tag readers, which remotely retrieve data. It is a method of identifying objects and transferring information about the object's status via radio frequency waves to a host database. RFID is not necessarily a direct replacement for bar codes, but as the costs of RFID systems continue to decrease, the functional utility of RFID will greatly surpass that of bar codes.

An RFID system is a set of components that work together to capture, integrate, and utilize data and information. This section describes some of them. The components are as follows:

- Sensors, Tags, Antennas, Readers.

- Connectors, Cables, Networks, Controllers.

- Data, Software, Information Services.

\subsection{RFID Tags}

An RFID tag (Kebo, Staša, Beneš, Švub, 2013) is a small device that can be attached to an item, case, container, or pallet, so it can be identified and tracked. It is also called a transponder. The tag (Beneš, Kubáč, Staša, Kebo, 2013) is composed of microchip and antenna. These elements are attached to a material called a substrate in order to create an inlay.

Tags are categorized into three types based on the power source for communication and other functionality.

- Active.

- Passive.

- Semi - passive.

- Semi - active.

\subsection{RFID Reader}

The second component (Thornton and Lanthem, 2006) in a basic RFID system is the interrogator or reader (Figure 3). Readers can have an integrated antenna, or the antenna can be separate. The antenna can be an integral part of the reader, or it can be a separate device. Handheld units are a combination reader/antenna, while larger systems usually separate the antennae from the readers. The reader retrieves the information from the RFID tag. The reader may be self-contained and record the information internally; however, it may also be a part of localized system such as a POS cash register, a large Local Area Network (LAN), or a Wide Area Network (WAN). 


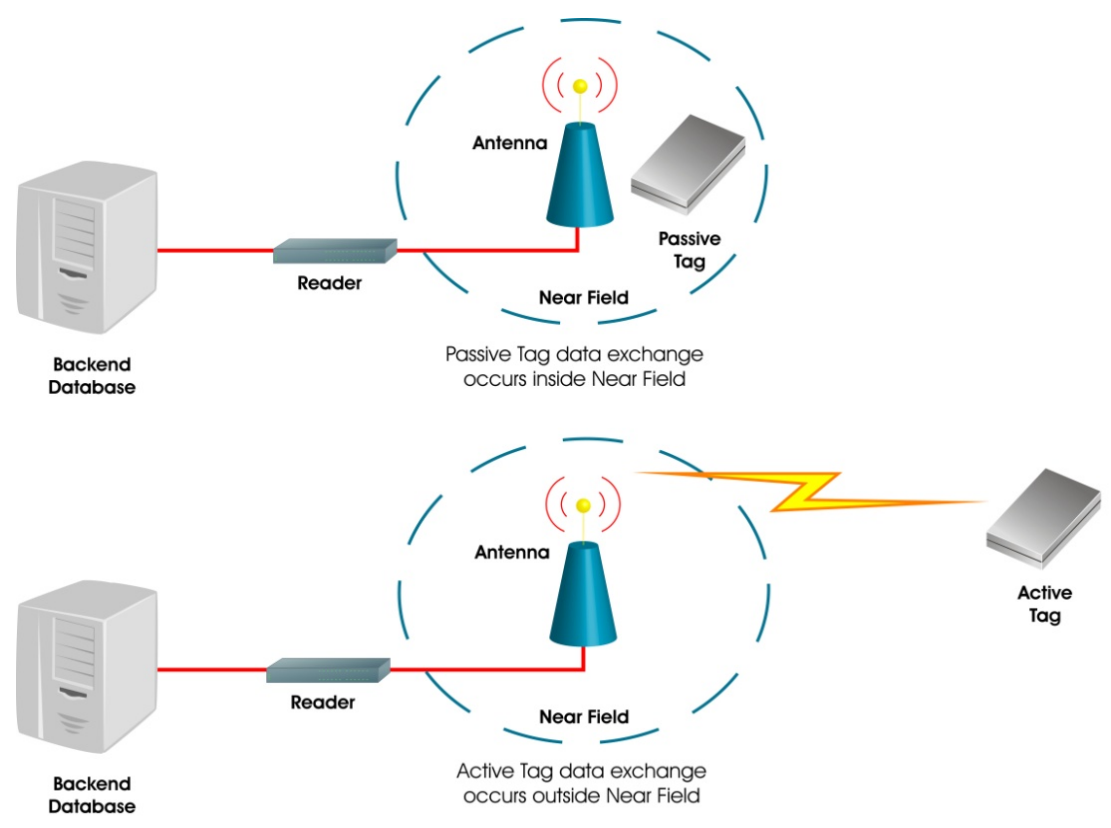

Figure 3. Passive and Active Tag Processes (Thornton and Lanthem, 2006)

\subsection{RFID Middleware}

Middleware is software (Kocur, Machula, Kulda, Vojtěch, 2010) that controls the reader and the data coming from the tags and moves them to other database systems. In our cases we have used the Aton AMP middleware. It carries out basic functions, such as filtering, integration and control of the reader. RFID systems work, if the reader antenna transmits radio signals. These signals are captured tag, which corresponds to the corresponding radio signal.

This is a very special (Michálek, Vaculík, 2008) software device enabling mutual communication between two and more applications. This device is marked also as a mediator between various application components. The core activity of such devices covers the linking and switching of various different applications or hardware components for exchange, record and data modification purposes. There is a RFID middleware located between reader and server/database or other software device. This can have various functions depending on complexity of the system.

We can say that middleware fulfils following functions:

- Masks the communication distribution of many cooperating parts of the system located in various physical places,

- Masks the heterogeneity of various hardware components, their different operational systems and communication protocols,

- $\quad$ Provides unified interface enabling easier system extension and its easier communication with world.

\section{Description of Measurements and AMP Model Configuration}

In order to achieve relevant outcomes, it was inevitable at first to design functional system enabling realization of single measurements under laboratory conditions. In order to comprehend single measurements, we have to define the principle they operate under and what is being detected by them.

\subsection{Description of Measurements}

At first (Koškár, 2013), we have to find out the readability of RFID tags of parcels placed in metal postal container at the moment of its passing through RFID gate with antennas. At second, we have to realise that we perform several types of measurements. These types differ in RFID tags orientation on parcels as well as by number of antennas; by their use tags are scanned. In order to ensure the credibility of measured results, each type of measurement is repeated 100 times and therefore each single of them is called partial measurement. We do have the type of measurement and 100 partial measurements within, from which we made statistical results. The relation between types of measurement and partial measurements: 
- Type: Placing of identifiers on the top of the parcel post: four antennas:

o Partial measurement No. 1

o Partial measurement No. 2

o Partial measurement No. 3

By accomplishment of single measurements, we obtained required data for deduction of results and recommendations. The accomplishment of measurements according to our requests needed certain preparation indeed. As for the preparation process, it was inevitable to select pasteboard boxes representing the parcels placed in postal container. In order to fill up the entire loading capacity, we needed 40 boxes of different size.

As each single parcel had to contain one RFID tag, we needed 40 passive UPM Raflatac DogBone RFID tags. The identification number (tagID) of each tag was re-programmed by use of hand RFID reader in order to get the other activities simplified. The structure of these IDs would be 30080000000000000000 00xx. As we used 40 parcels overall, the last two digits would be 00 to 40 , where the first value 00 would be assigned to launching RFID tag placed on container. At the same time, we were detecting the readability quality of particular RFID tags during the process of reprogramming. Thanks to that, we noticed, that one tag had much lower level of readability in comparison to other tags. This tag was assigned the value 01 of last two digits.

Following reprogramming process, we placed the tags to parcels. In order to prevent any damage of tags and at the same time, to ensure their fully functionality after realization of our measurements, we stick them by using of adhesive tape. We wrote the last two digits of tag's ID during the sticking of tag due to later identification and analyse. All the parcels were placed into container, whereby the parcel with lower readable tag (01) was placed on the very bottom of the container. Afterwards, ID's of tags were filed into MySQL database and configuration's Whitelists, by which we set the RFID reader exclusively for scanning of $40+1$ tags.

The very last step was the involvement of antennas. The upper two antennas were placed onto metal construction and the sides of antennas were attached to telescopic stands, by which we ensured RFID gate simulation.

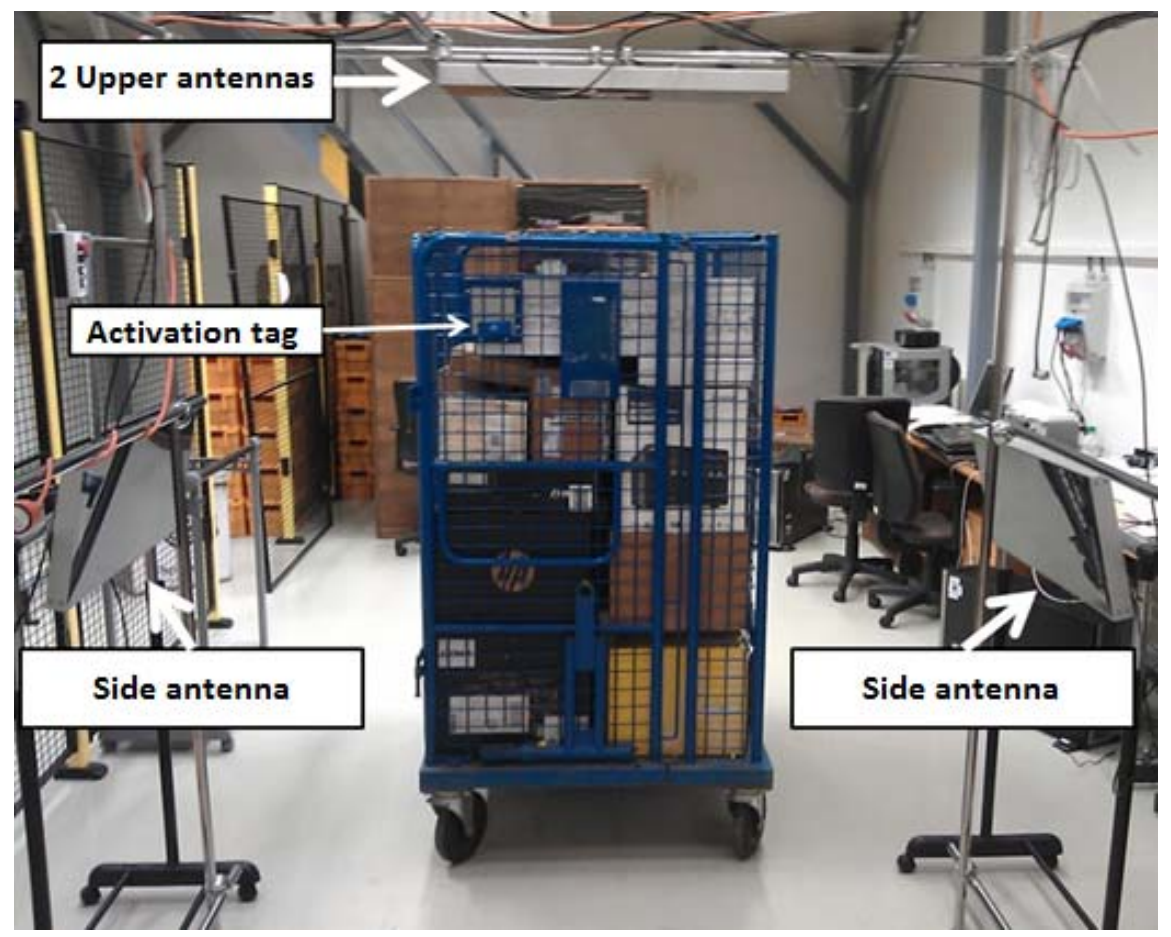

Figure 4. Preparing for measurements

\subsubsection{Hardware Part}

Hardware part consists of server, connecting cables, RFID gate (reader with antennas) and indeed with RFID tags placed on parcels and on plastic container. RFID reader Motorola was inevitable component of our hardware set. The reader consisted of four active antennas maximally in our configuration. 


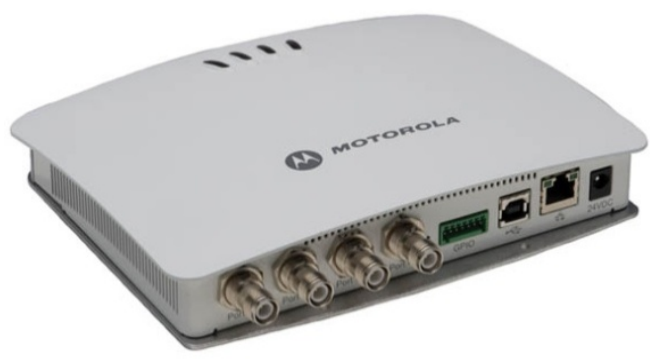

Figure 5. RFID reader Motorola FX7400 RFID reader Motorola FX7400

This RFID reader is characteristics by its compact processing, easy installation, high performance and besides, is able to be hooked up directly by use of data network cable (Power over Ethernet). Its use is applicable also in case of limited areas.

The very important part was to choose efficient and affordably priced RFID identifier. We used passive RFID tags UPM Raflatac DogBone applicable for such a laboratory tests. Their structure consists of antenna and integrated circuit. These components are with vapour on elastic sticky plastic paper, so the tags can be easily stuck directly to needed object.

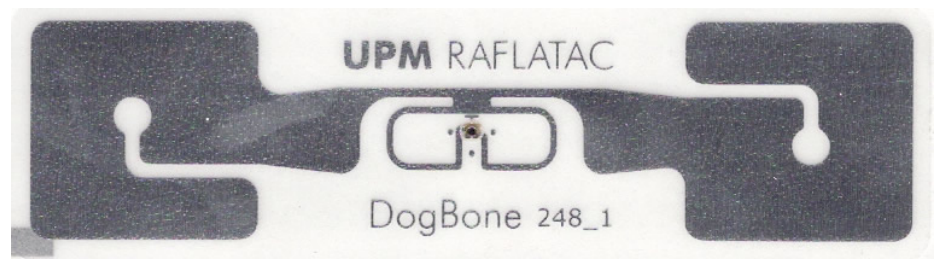

Figure 6. RFID tag UPM Raflatac DogBone

\subsubsection{Software Part}

As for the software parts, we used operation system MySQL database, middleware and web application. The mutual relations of particular components (items) are depicted in the most proper way on figure 7. What needs to be said is that this is only a very simplified model and not every item can be marked as elementary, because each of them consists of other parts.

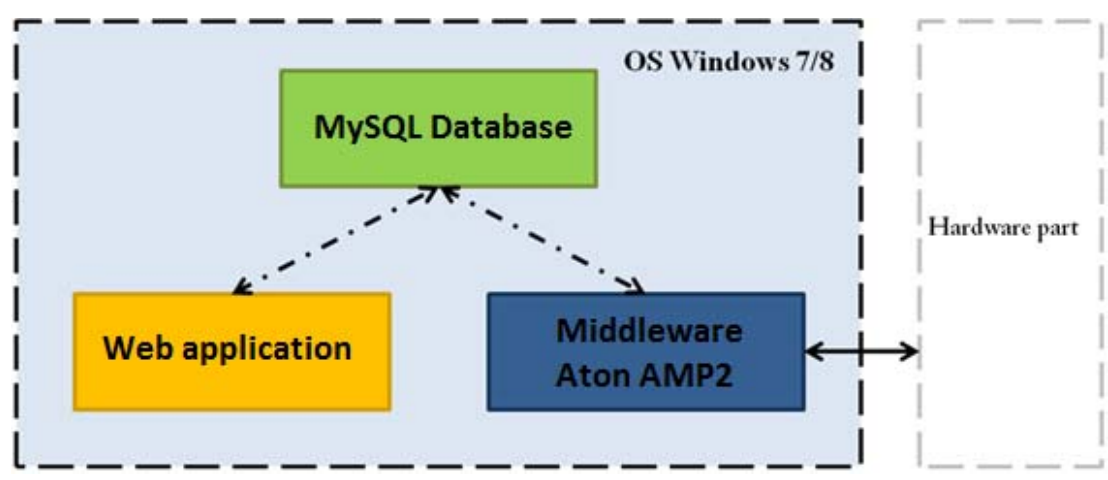

Figure 7. Software part

Operation system ensures the flow of overall model, particular software items run under the system. As can be seen, web application doesn't communicate with middleware directly, but data are exchanged between them through MySQL database. In order to get overall view, we will explain shortly the basic functions of particular items and system operation principle.

Middleware (Vaculík and Tengler, 2012) ensures communication between hardware and software part of our model. At the same time, it enables to set up the configuration itself, so by its use we define 
practically what, how and when should the particular hardware and software components operate. Considering the close collaboration of our department with company ATON spa, we chose middleware OnID or AMP that actually made our work with collected date much easier.

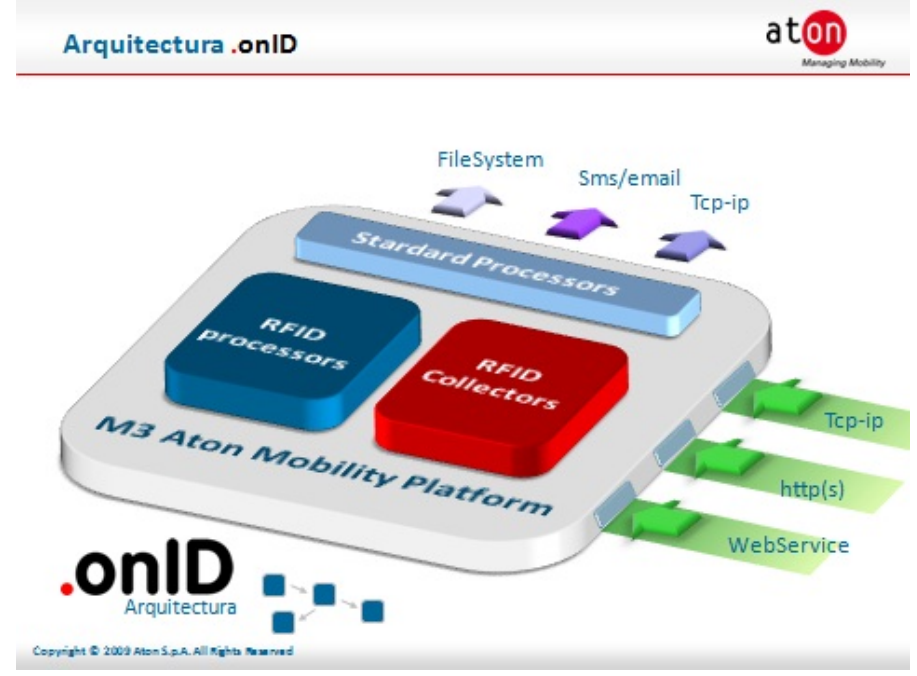

Figure 8. AMP platform

All the data obtained from RFID gate are stored into database as well as all the data sent by user through web application. These data are accumulated here and provided by request to web application and to middleware. MySQL database serves as a place for gathering of all the collected data waiting for further demand. Web application serves for presentation of all the data from database and its further processing due to need to accomplish analyse by user. In our case, the user also gives directions to start the single types of measurements through application.

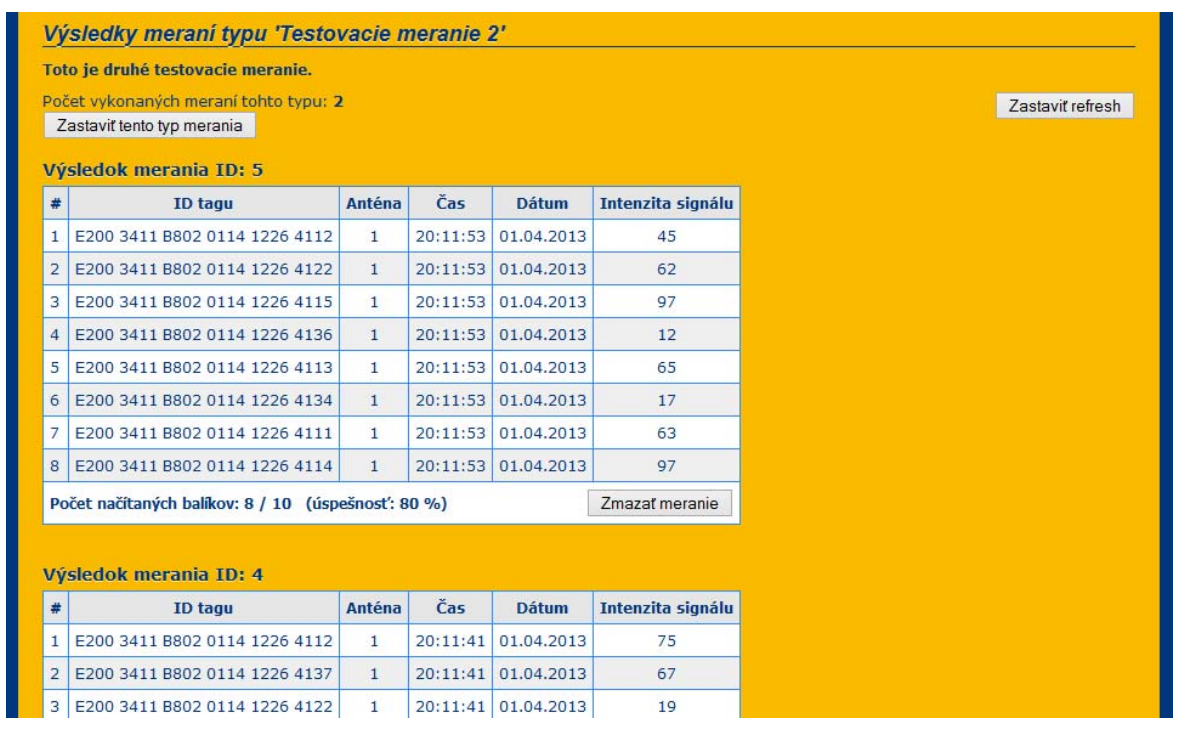

Figure 9. Web application (Koškár, 2013)

\subsection{AMP Model configuration}

Configuration of the model for readability measurement of parcel posts was designed in environment of AMP middleware. It was split into three parts:

- Launch of measurements,

- Capacity control and sound signalisation,

- Time formatting and recording into database. 


\subsubsection{Launch of Measurements}

The first module serves for initialisation of MySQL database, RFID reader as well as for detection, whether some type of measurement had been already launched. According to this finding, we define next procedure and following processes.

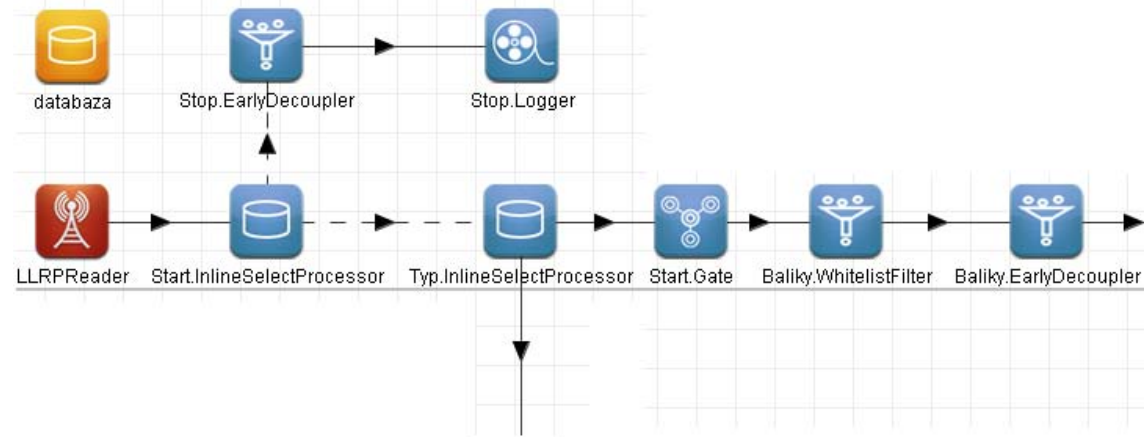

Figure 10. Launch of measurements (Koškár, 2013)

\subsubsection{Capacity control and sound signalisation}

The second (Koškár, 2013) module ensures us entering of records about new partial measurement of respective type of database. This section also defines when this partial measurement is finished and when the gate capacity closed again and what is being accomplished besides sound signalisation.

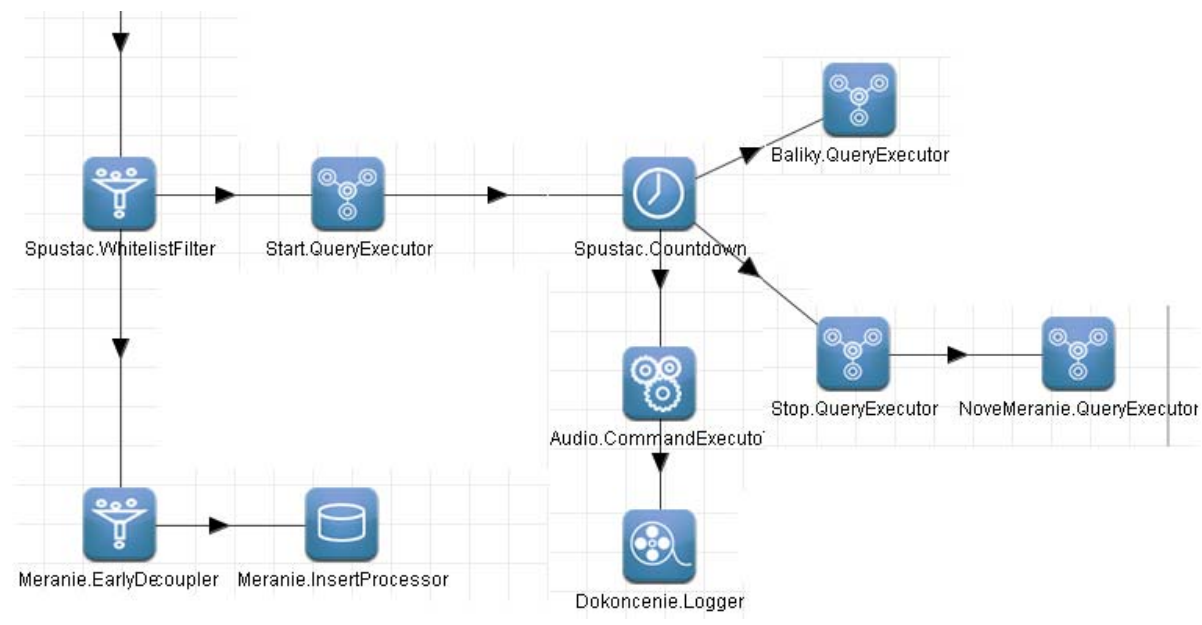

Figure 11. Capacity control and sound signalisation (Koškár, 2013)

\subsubsection{Time Formatting and Recording into Database}

The third module formats at first the date and time of scanning of each parcel and mainly ensures the entry of data about scanning of particular parcels in container into MySQL database.

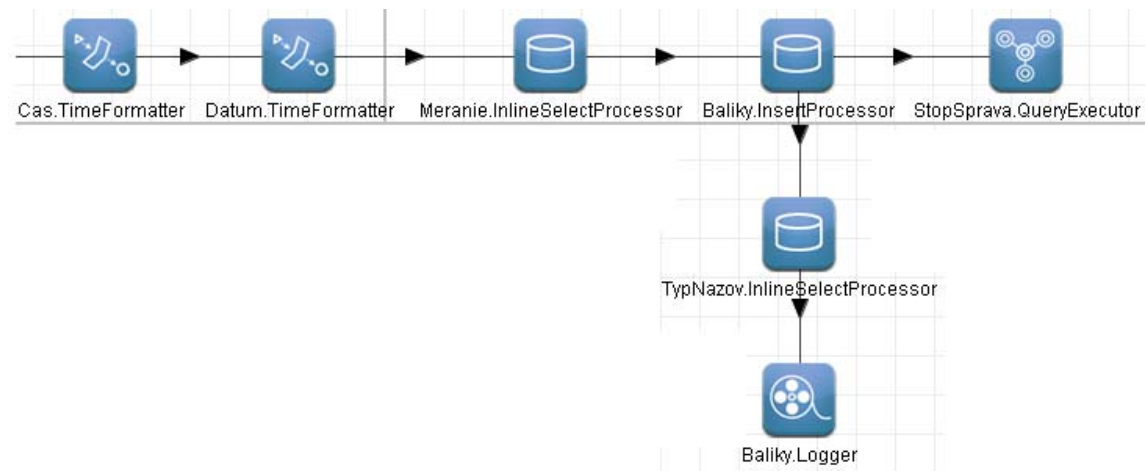

Figure 12. Time formatting and recording into database (Koškár, 2013) 


\section{Results from the Measurements}

Prior to launching of measurements themselves, we had performed a line of several testing measurements in order to detect the functionality of overall system. At the same time, we found out by use of these tests that intensity of reader's scanning set in configuration has a minimal effect on scanning of particular tags in container. Therefore we set this intensity at each measurement for $100 \%$ level.

Concerning the readability research of parcels placed in postal container, we performed the measurement for dependency of RFID identifiers placing on parcels as well as their orientation in regard to position of reading antennas. We performed following types of measurements:

1. Tags placed on the top side of parcels,

2. Tags placed on the bottom side of parcels with regard to bottom of the container,

3. Tags placed with edges towards all antennas,

4. Tags placed at the walls of container.

\subsection{Tags Placed on the Top Side of Parcels}

The choice (Koškár, 2013) of the first type was the one with RFID tags placed on the top side of parcels. We assumed that the results should be theoretically the best of all the types as the position of antennas was most favourable, considering radio frequency waviness and its impact to RFID tags.

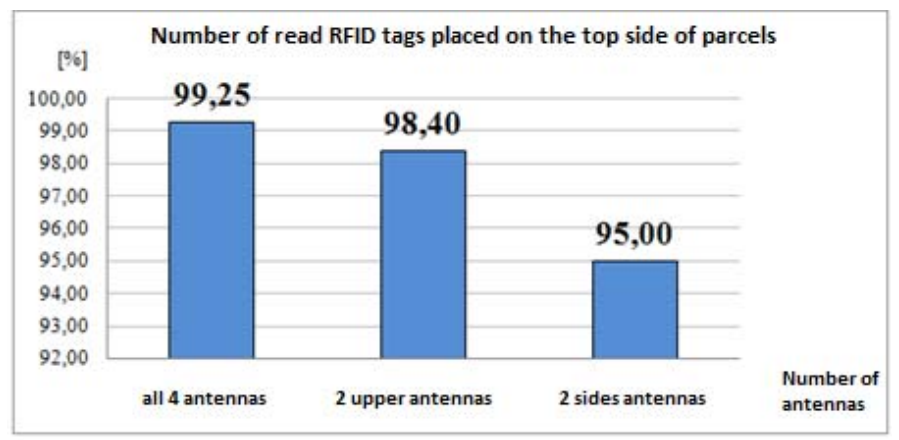

Figure 13. Results of measurements 1 (Koškár, 2013)

As we can see, the results of this type of measurement are indeed very positive. We measured the readability efficiency of $99,25 \%$ by scanning of the container with parcels with all four antennas. The only tag with weaker level readability was the one with tagID 01 . This was successfully read only 76 times out of 100. Signal was not strong enough so that the antennas could successfully detect at each measurement the parcel with weaker readable tag placed on the very bottom of the container. If we ignored this one particular tag, we would have achieved overall average readability attacking level of almost straight $100 \%$.

\subsection{Tags Placed on the Bottom side of Parcels with Regard to Bottom of the Container}

At this case (Koškár, 2013), we assumed moderate fall of readability. This assumption was not that much fulfilled at the very end.

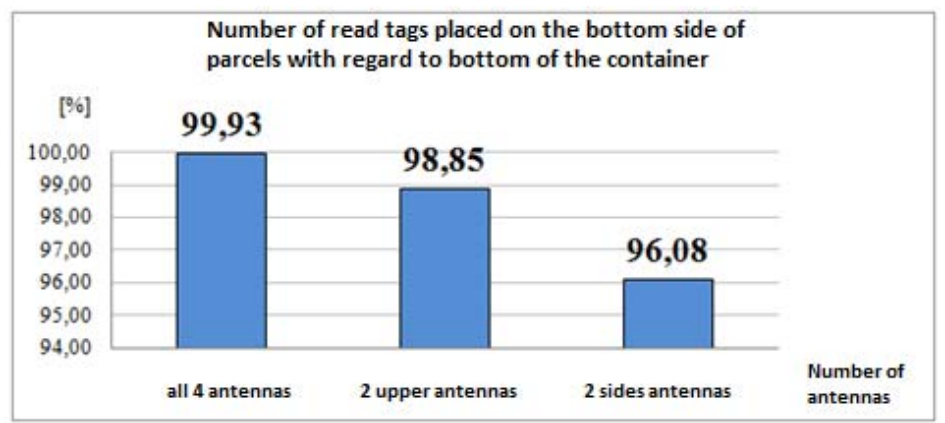

Figure 14. Results of measurements 2 (Koškár, 2013)

We can see, that the readability was not only reduced but even increased by scanning with all the antennas up to level 99,93\%. The most relevant influence on this outcome has indeed the problematic tag 01 that was placed again at the very bottom of the container, but this time the tag was directly touching the bottom of container. The presence of the tag closer to floor and reflection of signals either from metal construction of container or from the ground very likely caused its $100 \%$ readability by scanning with all four antennas. 


\subsection{Tags Placed with Edges Towards All Antennas}

At this variant, we made our decision to make the reading of the tags more difficult with their placing vertically to all the antennas. The tags were replaced on sides of parcels relating to back side of the container. Besides, the previous type of measurements proved that just by linking of side antennas had the orientation of tags moderate influence of readability. Therefore we stuck the tags also into horizontal position.

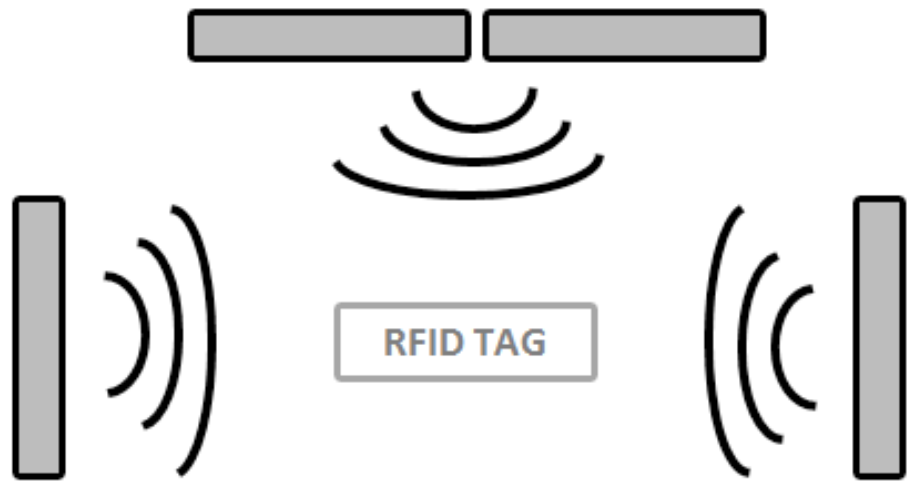

Figure 15. Configuration of measurements 3

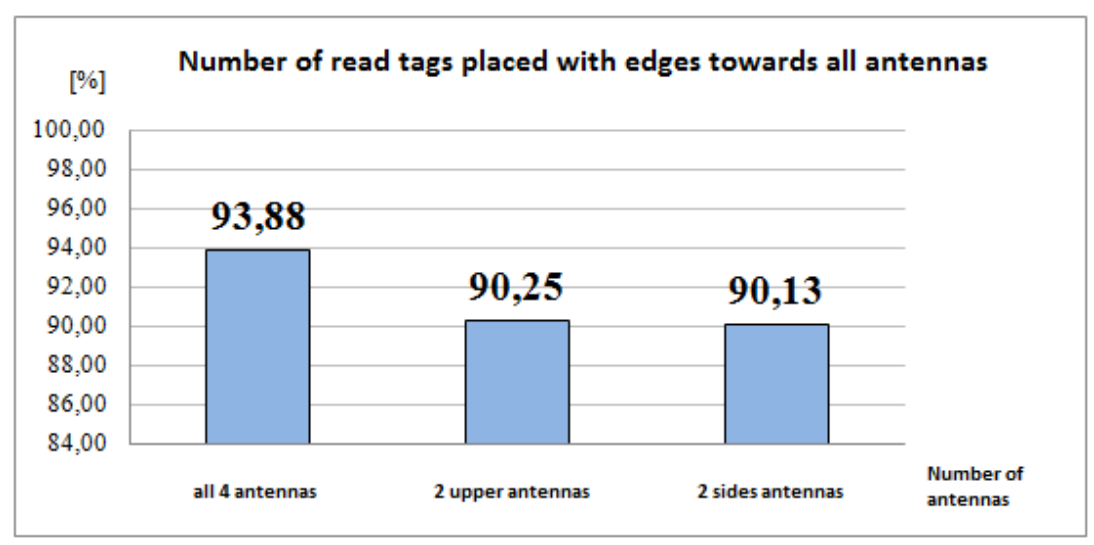

Figure 16. Results of measurements 3 (Koškár, 2013)

Not even at this cased dropped the readability under $90 \%$ what can still be considered for a very good result.

\subsection{Tags Placed at the Walls of Container}

We detected at previous types of measurements, that the barred metal wall of container from which the signal reflected had the major influence for scanning of parcels. Therefore we decided that at the last variant, the most of RFID tags of the parcels would be placed at the walls of container. We assumed that this setting of parcels would have the most significant influence with regard to readability.

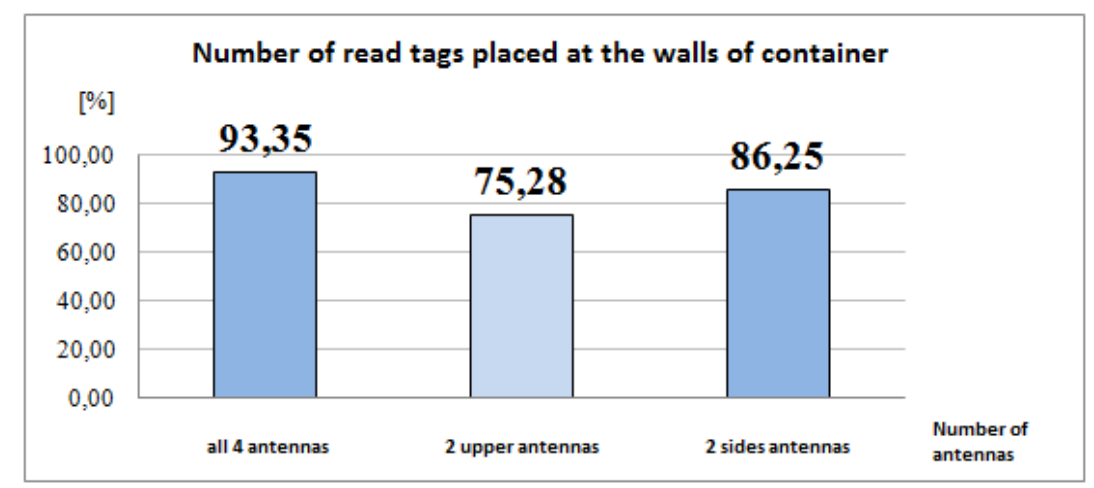

Figure 17. Results of measurements 4 (Koškár, 2013) 
The readability of tags didn't drop significantly by scanning with all four antennas, it just dropped to still very satisfying level of $93,35 \%$. Despite quite a good average outcome of readability, we have to state that the tags placed at metal parts behave unpredictable from readability point of view.

On the next table we can see the result from all measurements, which were made at the laboratory conditions.

Table 1. Results of measurements (value in \%)

\begin{tabular}{|c|c|c|c|}
\hline \multirow{2}{*}{ Type of measurements } & \multicolumn{3}{|c|}{ Number of antennas } \\
\cline { 2 - 4 } & 4 antennas & 2 upper antennas & 2 sides antennas \\
\hline \hline 1 & 99,25 & 98,4 & 95 \\
\hline 2 & 99,93 & 98,25 & 96,08 \\
\hline 3 & 93,88 & 90,25 & 90,13 \\
\hline 4 & 93,35 & 75,28 & 86,25 \\
\hline
\end{tabular}

\subsection{Proposed Placing of tags on Parcels and Lay-Out of Antennas of RFID Gate}

Based (Koškár, 2013) on results of previous measurements, we could perform a measurement dealing with most convenient placement of RFID tags on parcels in container along with a placement on antennas. Tags were placed upon top side of parcels. So that the results of measurements were not deformed by any weaker readable tag $(01)$, we made a decision at recommended configuration to change this tag for the other one. At first, we scanned exclusively just by use of two top antennas. After 100 repetitions, we recorded average detection of parcels at level 99,8\%. Then, we placed another two antennas upon second end of top construction of RFID gate, by which we ensured vertical scanning by all four antennas at once. Two antennas were indeed placed at input and two at output of RFID gate, by which we achieved approximately the same long scanning interval of each tag in container. We performed the measurements 100 times. We achieved at such a configuration the average level of readability equal $100 \%$. The very same results were achieved also in case, when the tags were turned so that they were placed on the bottom side of parcels - in direction to bottom of container.
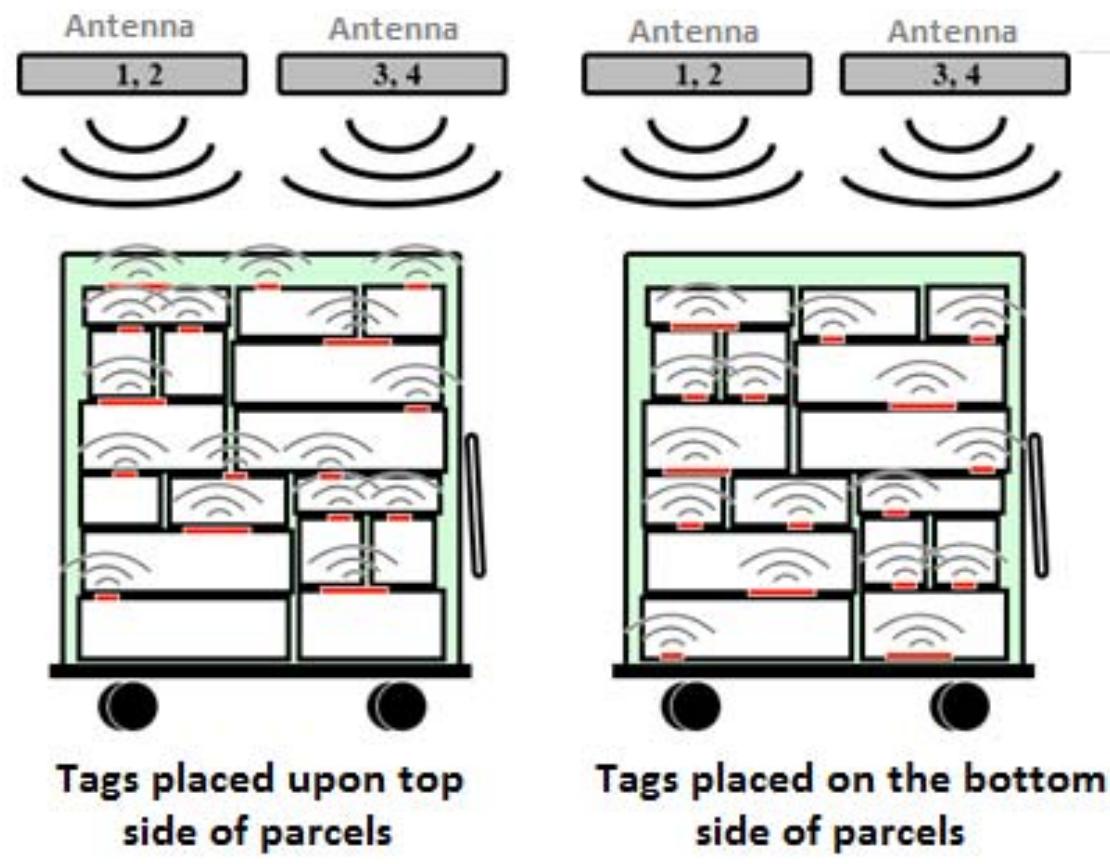

Figure 18. Proposed placing of tags on parcels 


\section{Conclusions}

We can state that introduction of passive radio frequency identification of parcel posts in postal operation is technically feasible as a very high level of readability was achieved by scanning of particular parcels under laboratory conditions, reaching equal $100 \%$. The results are very dependant indeed on specific placement of RFID tags on parcels in container where are they placed and at the same time on placement of antennas of RFID reader. Another significant gained knowledge is that optimal solution is with utilization of four RFID antennas placed on top side of RFID gate enabling scanning of tags in vertical direction. Two antennas were placed at input and two at output of RFID gate. Thereby we ensured equally long scanning internal of each parcel in container resulting in a very high overall level of readability. Such a solution wouldn't be technically demanding under real conditions in operation. Besides we found out that metal parts of container construction represent the prime problem of parcels' scanning in container. Signal reflected in this case significantly that means the potential scanning/ un-scanning of parcels would be very tough to predict. On the contrary, the highest percent efficiency of scanning was recorded in case of RFID tags placed on top and bottom side of parcels. Under these conditions, the signal is not interfered by metal parts of container construction and the parcels are scanned without any serious problems even in case of only two top antennas utilization. At the end of this article I would like to thank my diploma student Ing. Lukáš Koškár for high-quality processing of the diploma thesis and the proposed solutions.

\section{Acknowledgements}

This article was created to support project named as:

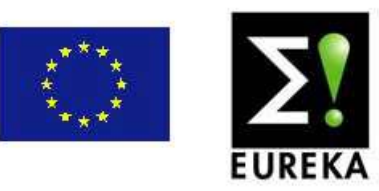

E!7592 AUTOEPCIS - RFID Technology in Logistic Networks of Automotive Industry (RFID technológie v logistických siet'ach automobilového priemyslu)

This article was created in response to tackle a project co-funded by the EU titled "The Quality of Education and Human Resources Development as Pillars of the Knowledge Society" at the Faculty PEDAS of the University of Zilina, ITMS 26110230083
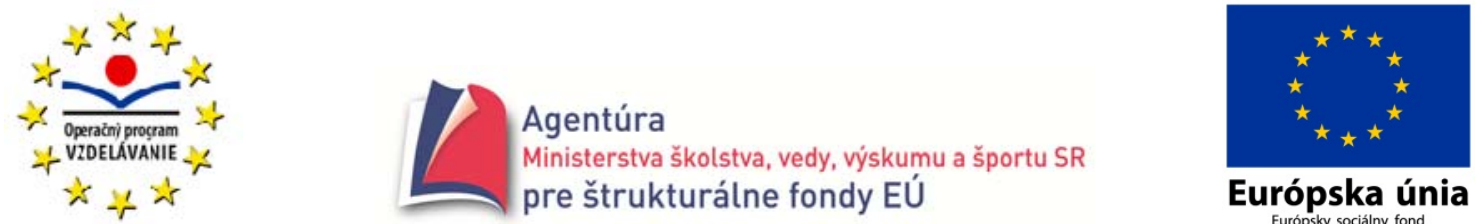

Modern education for the knowledge society / project is co-financed by the EU

\section{References}

1. Beneš, F., Kubáč, L., Staša, P., Kebo, V. (2013). RFID and Augmented Reality. In: Proceedings of the 14th International Carpathian Control Conference (ICCC), Rytro, Hotel Perła Południa, Poland, May 26-29. Vienna: IEEE, pp. 186-191.

2. Bolarín, F.C., Frutos, A.G., Lisec, A. (2011). Assessing the impact of prices fluctuation on demand distortion within a multi-echelon supply chain. Promet-Traffic-Traffico. 23(2), pp. 131-140.

3. Hunt, V., Puglia, A., Puglia, M. (2007). RFID: A Guide to Radio Frequency Identification. New Jersey (USA): John Wiley \& Sons, Inc. 201 p. 
4. Kebo, V., Staša, P., Beneš, F., Švub, J. (2013) RFID Technology in Logistics Processes. In: Proceedings of the $13^{\text {th }}$ International Multidisciplinary Scientific GeoConference SGEM, Albena, Bulgaria.

5. Kendra, M., Lalinská, J., Čamaj, J. (2012) Optimization of transport and logistics processes by simulation. In: ISTEC; Proceedings of the 3rd International Science, Technology and Engineering Conference, Dubai, United Arab Emirates (UAE), December 13-15, 2012 (pp. 886-892). [Online]

6. Klapita, V., Mašek, J. (2012) Processes solution in the warehouse by the queuing theory application. In: Horizons of Railway Transport: scientific papers (pp. 64-6), volume 3, no. 1. ISSN 1338-287X

7. Kocur, Z., Machula, V., Kulda, J., Vojtěch, L. (2010) Analysis of Influence of Disturbance Level on Data Transmission in Wireless Networks. In TSP 2010 - the $33^{\text {rd }}$ International Conference on Telecommunications and Signal Processing. Budapest: Asszisztencia Szervező Kft., pp. 292-296.

8. Kolarovszká, Z., Fabuš, J. (2011) IT service management in conjunction with the universal postal service in Europe. In: Postpoint 2011, the $9^{\text {th }}$ International Scientific Conference; International meeting of postal administration representatives, university educators and researches, Žilina, Slovakia, September 19-20, 2011. Žilina: University of Žilina, pp. 114-122.

9. Koškár, L. (2013). Application of identifying parcels through RFID technology and their appropriate placement in the mail container in terms of readability: Diploma thesis, Žilina, 2013, University of Žilina. Faculty of Operation and Economics of Transport and Communications; Department of Communications. Tutor: Kolarovszki Peter, Ing. Ph.D.

10. Madleňák, R., Švadlenka, L. (2009) User Acceptance of Internet advertising in Czech Republic [Akceptace internetové reklamy uživateli v České republice]. In: Economics and Management: [Ekonomie a management = vědecký ekonomický časopis], volume 12, no. 1, pp. 98-107. ISSN 1212-3609.

11. Maslaric, M., Groznik, A., Brnjac, N. (2012) Distribution channel reengineering: A case study. Promet-Traffic-Traffico, 24(1), pp. 35-43.

12. Michálek, I., Vaculík, J. (2008) RFID planning levels for postal and courier services. In: Future Role of Postal Services in the Face of New Market Conditions and Communication Technologies, Pardubice, Czech Republic, December, 2008, pp. 144-151. Pardubice: University of Pardubice.

13. Thornton, F. \& Lanthem, Ch. (2006) RFID Security. Rockland (MA, USA): Syngres Publishing, Inc. 229 p.

14. Vaculík, J., Tengler, J. (2012) Potential of new technologies in logistics services. In: Conference Proceedings of the 'CLC 2012' - Carpathian Logistics Congress, November $7^{\text {th }}-9^{\text {th }} 2012$, Jesenik, Czech Republic, EU, Ostrava: TANGER.

15. Vojtěch, L., Neruda, M. (2010) Application of Shielding Textiles for Increasing Safety Airborne Systems - Limitation of GSM Interference. In: The Ninth International Conference on Networks (ICN 2010). Los Alamitos: IEEE Computer Society, pp. 157-161. 